\title{
Well-log based rock physics template of the Vienna Basin and the underlying Calcereous Alps
}

\author{
Nebojsa Tucovic ${ }^{1}$ Nina Gegenhuber ${ }^{1}$
}

Received: 30 December 2016/ Accepted: 30 March 2017/Published online: 13 April 2017

(c) The Author(s) 2017. This article is an open access publication

\begin{abstract}
In this study, the ratio of compressional and shear wave velocity versus acoustic impedance as rock physics template for northern part of the Vienna Basin has been derived for siliciclastic rocks based on formation evaluation of well-log data. The results have been verified through wells in different areas drilled in various depths. Additionally, depositional sequences like prograding deltas and braided rivers have been plotted onto the rock physics template to illustrate the effect of changing shale volume. Carbonates below the basin have been included into the study and results from previous projects, based on laboratory data and petrophysical models on certain lithologies in the Vienna Basin, have been used to compare the outcome. The result is a rock physics template which includes important properties such as porosity, true vertical depth and fluid type from log data and which is considered useable throughout different areas and various lithologies of the Vienna Basin.
\end{abstract}

Keywords Rock physics template · Formation evaluation · Vienna Basin · Depositional sequences

\section{Introduction}

Seismic measurements are the most frequently used methods in exploration activities in the oil and gas industry. More advanced and complex tools to get more qualitative as well as quantitative information out of a seismic

Nina Gegenhuber

nina.gegenhuber@unileoben.ac.at

1 Chair of Applied Geophysics, Montanuniversitaet, Leoben, Austria cube have been developed through the last decades. Ødegaard and Avseth (2009) published the so-called rock physics template (RPT). Their idea was to create basin and lithology-dependent templates mainly with elastic properties of rocks (most commonly the ratio of compressional and shear wave velocity $\left(v_{\mathrm{p}} / v_{\mathrm{s}}\right)$ and acoustic impedance (AI)) of rocks. These templates, which are able to indicate fluid and lithology trends, can then be used for interpretation of seismic data from the corresponding basin or lithology. In further consequence rock physics templates have been widely used in the exploration activities within the industry. Numerous studies have been conducted. Most of the studies used elastic properties in siliciclastic rocks to construct the templates with petrophysical models (Avseth et al. 2009; Chi and Han 2009; Gupta et al. 2012).

Rock physics templates for carbonate reservoirs have been created too. Ba et al. (2013) created multiscale rock physics templates for carbonates and validated them with laboratory, well and seismic data. Gegenhuber and Pupos (2015) determined elastic properties with Hashin and Shtrikman (1962) bounds and derived $v_{\mathrm{p}} / v_{\mathrm{s}}$-acoustic impedance-based rock physics templates from laboratory data for three different carbonate types from Austria under dry and wet conditions, applied additionally on log and seismic data (Pupos 2015).

Avseth and Veggeland (2015) introduced additional rock stiffness/rock impedance (PEIL) and fluid softness/ fluid impedance (CPEI) attributes which honour fundamental rock physics from $v_{\mathrm{p}} / v_{\mathrm{s}}-\mathrm{AI}$ rock physics templates. The combined use of these two attributes can help differentiate between fluid and lithology anomalies in the rock physics template. Additionally, Avseth and Carcione (2015) used rock physics templates to get an understanding of complex kerogen-rich Jurassic source rocks from the Norwegian Shelf. $v_{\mathrm{p}} / v_{\mathrm{s}}$-acoustic impedance behaviour 
throughout the different processes in the compaction and hydrocarbon generation of source rocks helps to determine the maturity of the rock and generation of hydrogen.

Hermana et al. (2016) derived rock physics templates from attenuation parameters (SQp and SQs) and applied it to a real dataset from Malay Basin. They concluded that their attenuation-based rock physics templates derive better lithology and fluid separation results than conventional $v_{\mathrm{p}} /$ $v_{\mathrm{s}}$-acoustic impedance rock physics templates on the considered dataset. Tucovic et al. (2016) created resistivity-acoustic impedance rock physics templates based on deep reading logging while drilling data as a foundation for further work of real-time template-based logging while drilling interpretation for enhanced geosteering operations.

Although all these rock physics templates are able to distinguish between gas and water and different lithologies, they are still not suitable for determining oil saturation within seismic data and are mainly usable just for one lithology with certain properties throughout the basin.

As pointed out, RPTs are a valuable tool in seismic exploration industry. The goal of this paper is to create a rock physics template which is applicable in the whole pull-apart basin in Lower Austria and the underlying Calcareous Alps with well-log based formation evaluation. Parts are evaluated with derived RPTs out of laboratory data. Depth-related trends are considered as well as different lithologies with their evaluated properties from formation evaluation of the logs. Depositional sequences like prograding deltas or braided rivers are visualized on the created template to validate it.

\section{Geology of the Vienna Basin}

Vienna Basin is a $200-\mathrm{km}$-long and $60-\mathrm{km}$-wide rhombic pull-apart basin located in the northeast part of Austria. It is a mature basin operated by OMV since the 1930s. The basement of the Vienna Basin is the Bohemian Massif overlain by the autochthonous sedimentary cover which is Jurassic to Cretaceous age (Ladwein 1988). This sedimentary cover is followed by the Flysch Zone (Lower Cretaceous-Eocene) and finally the Northern Calcareous Alps (Permian-Cretaceous), which have been overthrusted during the northwest-directed transportation in lower Cretaceous-Oligocene age with piggy back basins on their back. After the thrusting in the middle Miocene (Badenian), north south compression with associated compensation movement of the nappes to northeast occurred. This resulted in separation of the Northern Calcareous Alps and Carpathians associated to extension and pull-apart effects (Wessely 2006). During this time, main subsidence and sedimentation of clastic sediments as a result of transgressive/regressive cycles due to sea level changes took place (Kreutzer 1992). Thus, the sediments of the Vienna Basin are of Neogene age and reach $5-6 \mathrm{~km}$ at some locations (Ladwein 1988).

Early stages of basin development in Ottnangian and Karpatian are dominated by lacustrine to fluvial environment while in Badenian (Middle Miocene) transgressive/ regressive cycles with prograding deltas in marine environment are dominating (Sauer et al. 1992). Here the most reservoirs in the Vienna Basin are saturated and the sand horizons are numbered. An example is 16th TH (Tortonian horizon) which consists of many on-lapping layers, which are composed of prograding delta front sequences and separated by flooding events. By the side, already more than 400 wells have been drilled into this 16 th $\mathrm{TH}$, also called the Matzen sand and the associated Matzen giant field which has been discovered in 1949 and is one of the largest multi-pool oil and gas field onshore Europe (Kienberger and Fuchs 2006). In the following Sarmatian, marine environment evolved to brackish water conditions and lead to lacustrine and fluvial deposits in the Pannonian (Sauer et al. 1992). Up to 20 sand horizons have been deposited and numbered here throughout the basin. After the Sarmatian, during the Pannonian sedimentation continued in lacustrine environment with deposition of fluviatile clastic sediments.

Besides the huge number of reservoirs within the Neogene part of the succession, commercial pay zones have been found within the Triassic dolomites underneath the Basin in the allochthonous nappes (Ladwein 1988). This dolomite called the "main dolomite" is formed in shallow lagoon areas and shallow water zones with very low porosity (Gegenhuber and Pupos 2015). Main source rocks in the basin are the Upper Jurassic (Malmian) marls in the autochthonous part of the section (Hamilton et al. 1999), which are generated below the basin in depths of 3-6 km (Ladwein 1988). Sachsenhofer (2001) identified a geothermal gradient of the basin of $30^{\circ} \mathrm{C} / \mathrm{km}$.

\section{Data and methodology}

\section{Data}

Data used are wireline log data from the northern part of Vienna Basin. Most of data are available from Field A, which is situated on a structural high. Thus, wells which have been used for creation of rock physics templates from this field have reached true vertical depths (TVD) of about $2.3 \mathrm{~km}$. Other fields are located in deeper areas of the basin, mainly on structural low, but still in the northern part. One well per field have been used in Field B (true vertical depth of about $4.1 \mathrm{~km}$ ), Field C and D (true vertical depths of about $3 \mathrm{~km}$ ). A simple sketch to illustrate 


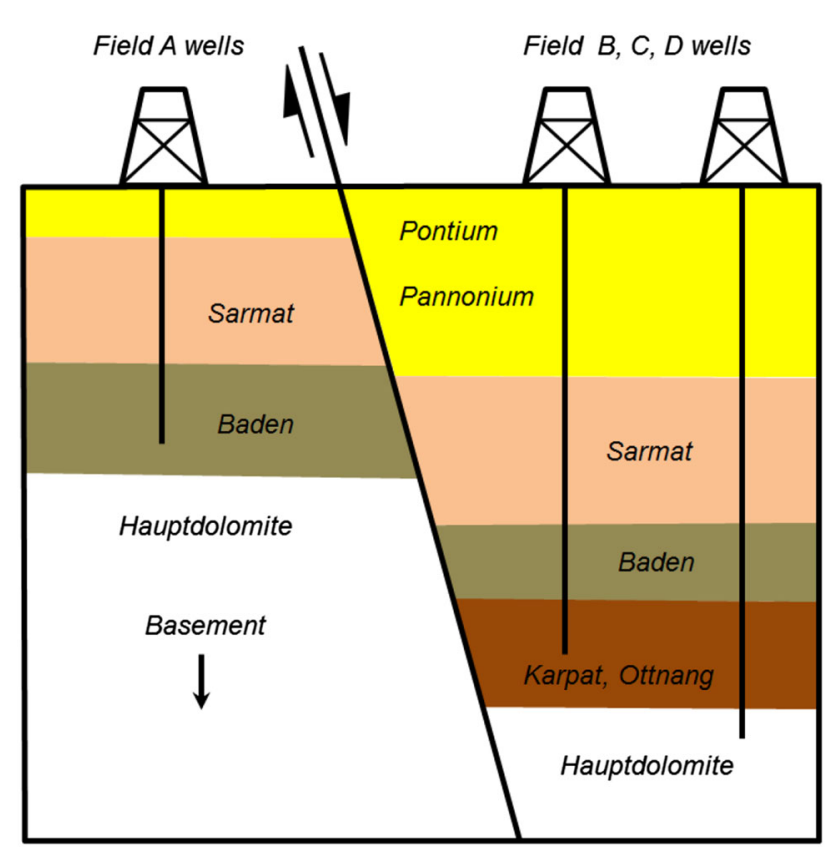

Fig. 1 Simple sketch illustrating the shallow Field $A$ wells on structural highs and Field $B-D$ wells on structural lows

the wells from different fields is shown in Fig. 1. The three wells in other areas of the basin (Field B, C and D) have been mainly used to evaluate the rock physics templates created with detail-evaluated wells from shallower areas from Field A because they encountered the same and similar siliciclastic rocks in much greater depths.

Table 1 shows the encountered formations and their horizons within the wells with the corresponding ages. Ages in the second column are from Central Paratethys nomenclature. Third column indicates the availability of hydrocarbons within the corresponding formations throughout the basin. In the last column the four fields are indicated which have the necessary data (shear velocity was the limiting factor) to create a rock physics template. As visible, "the main dolomite" from the Calcareous Alps beneath the basin has been drilled in the deep well in Field D too.

\section{Methodology}

\section{Formation evaluation of Field A wells}

To create a rock physics template from log data alone, it is necessary to complete a full formation evaluation of the investigated wells. This has been done with well measurement data from Field A. Formation tops, lithology discrimination, reservoir identification and fluid type and saturation have been fully determined within the Field A. The next step was to pick out shale and sand intervals to create model rock physics template shale and sand lines. These have been picked after the criteria defined in
Table 2. Additionally, sand has been differentiated after the various fluid contents (gas, oil, water).

In Fig. 2, an example of log representation of a hydrocarbon reservoir with surrounding shale deposited in early Miocene is shown. The first track shows picked lithology and fluid intervals for the rock physics template. This reservoir sand has gas- and oil-bearing zones and is overand underlain by shale layers.

With data from shale and sand (water-oil-gas) horizons from Field A, a scatter plot with four variables (resistivity, acoustic impedance, density and $v_{\mathrm{p}} / v_{\mathrm{s}}$ ) and two-dimensional combinations are determined. It was used to see where the best fluid and lithology separation can be achieved. As used by numerous studies in the past, $v_{\mathrm{p}} / v_{\mathrm{s}}-$ acoustic impedance crossplot has shown best results for fluid and lithology discrimination.

\section{Choosing the right two-dimensional crossplot for differentiation}

Figure 3 shows scatter plot with resistivity, acoustic impedance, $v_{\mathrm{p}} / v_{\mathrm{S}}$ ratio and density of the picked fluid-discriminated sand horizons and shale layers. It is clearly visible that green (oil reservoirs) and red (gas reservoirs) points are plotting always in areas of higher formation resistivity. Blue data points, which represent water-bearing sand horizons are slightly separated from shales coloured in brown. Note the significant oil/gas separation in densityincluded crossplots. Resistivity-included crossplots separate well between hydrocarbon and water. Thus, densityresistivity and acoustic impedance-resistivity crossplots (indicated with a red dashed circle) are very good fluid discriminators. On the other side, lithology (shale-sand) is not sufficiently separated in these crossplots. From first look onto the crossplots best results regarding lithology discrimination are reached at acoustic impedance $-v_{\mathrm{p}} / v_{\mathrm{s}}$ and density $-v_{\mathrm{p}} / v_{\mathrm{s}}$ crossplots (marked with the blue dashed circle). Thus, for this study standard acoustic impedance $-v_{\mathrm{p}} / v_{\mathrm{s}}$ crossplot is chosen.

\section{Modelling the rock physics template with well data from Field $A$}

In the next step, elastic data from the picked horizons from formation evaluation in wells from Field $\mathrm{A}$ is plotted onto a $v_{\mathrm{p}} / v_{\mathrm{s}}-\mathrm{AI}$ crossplot. Figure 4 shows lithology-discriminated data points from these wells including shale and sand. Shale and sand lines have been fitted to the data. Shale line is modelled above the shale data points (brown) because below this line the shale is getting mixed with silt and sand. Sand line on the other side has been modelled below the water-saturated sand points because above the sand is getting mixed with clay. 
Table 1 Encountered and evaluated formations within the study which have been used for creation of rock physics templates

\begin{tabular}{llllll}
\hline Age & Age (Tethys) & Reservoir & Subage/formation & Horizons & Elastic data available \\
\hline Miocene & Pontian & - & Pontian & - & - \\
& Pannonian & $\mathrm{G}$ & Middle Pannonian & Middle Pannonian horizon & Field A \\
& & $\mathrm{G}$ & Lower Pannonian & Lower Pannonian horizon & Field A \\
& Sarmatian & $\mathrm{O} \& \mathrm{G}$ & Upper Sarmatian & Sarmatian horizon & Field A \\
& & $\mathrm{O} \& \mathrm{G}$ & Lower Sarmatian & Sarmatian horizon & Field A \\
& Badenian & $\mathrm{O}$ & Buliminen Rotalien zone & - & Field A, B (deep), C (deep) \\
& & $\mathrm{O} \& \mathrm{G}$ & Sandschaler zone & Tortonian horizons & Field A, B (deep), C (deep) \\
& & $\mathrm{O} \& \mathrm{G}$ & Upper Lageniden & Lower Tortonian horizon & Field A, B (deep), C (deep) \\
& Karpatian & - & Aderklaa Conglomerate & - & Field A, B (deep), C (deep) \\
& & G & Aderklaa formation & - & Field C (deep), D (deep) \\
& Ottnangian & $\mathrm{O}$ & Gaenserndorf formation & - & Field C (deep), D (deep) \\
& Eggenburgian & - & Bockflies formation & - & Field D (deep)
\end{tabular}

All used formations in this study except the Triassic "main dolomite" have been deposited during the Miocene. Most reservoirs have been deposited in mid-Miocene during Badenian time

$G$ gas, $O$ oil

Table 2 Lithology and fluid discrimination criteria within the logs

\begin{tabular}{ll}
\hline Shale & $>60 \%$ Vsh \\
Sand_water-bearing & $<20 \%$ Vsh \& Sw $>80 \%$ \\
Sand_gas-bearing & $<20 \%$ Vsh \& Sw $<50 \%$ and logs indicate gas \\
Sand_oil-bearing & $<20 \%$ Vsh \& Sw $<50 \%$ and logs indicate oil \\
\hline
\end{tabular}

Thus, between these two lines on the crossplot the lithology is a mixture between sand and shale. The scattering of the sand-shale data points results from the fact that sand and shale lithologies are hardly clean in the field data (100\% sand/clay content). As shown in Table 2, shale horizons have been picked, if shale volume is bigger than $60 \%$. Red line represents $100 \%$ gas saturation in sands and is modelled below the picked gas-bearing reservoir intervals because they are not $100 \%$ gas-saturated. Note the green points slightly below the $100 \%$ water saturation sand line which represent picked oil-bearing reservoirs, most of them in Badenian ages.

After the curve fitting and determination of corresponding shale, sand (water and gas) lines for the Field A lithologies in the Vienna Basin, additional information of well-log interpretation have been used to model other relevant properties onto the template. Unlike Fig. 4 which shows just picked sand and shale lithologies, the four crossplots in Figs. 5 and 6 show all data points from wells within the Field A with modelled shale and gas/water sand lines.

In each crossplot different colour scales have been used which have been delivered from formation evaluation of the Field A wells. Left crossplot in Fig. 5 has total porosity as colour scale with determined porosity isolines. The crossplot on the right in Fig. 5 shows the same data points from wells from Field A with true vertical depth as colour scale. Here it is more difficult to distinguish between different TVD trends resulting in higher uncertainty of the true vertical depth trendlines. Isolines are directly drawn in the plot, using the colour code from the porosity and depth.

In the two crossplots in Fig. 6, same data from Field A as in Fig. 5 is plotted with shale volume (left) and water saturation (right) as colour scale. As excepted the shale volume and the water saturation values show the predicted plotting behaviour. Water-saturated formations (shales and water-saturated sands) plot above the blue water line and below the shale line while hydrocarbon-saturated reservoirs plot below. Low shale volume (where clean sand can be assumed) fits the sand line (and the gas-bearing direction) quite well. Exception is some shallow low shale areas which are indicated in the crossplot. Here it is assumed that the compressional velocity measurements are not valid anymore because of the low compaction and high porosity of the formation.

Validating the rock physics template with deeper wells from Field B, C and D

In the next step, the determined shale and sand lines from wells in Field A have been validated with wells, which drilled the same and similar siliciclastic formations in bigger depths. Each crossplot in Fig. 7 shows data from one well drilled in different fields and in different area of the northern part of the Vienna Basin. As described in the data chapter before, these 


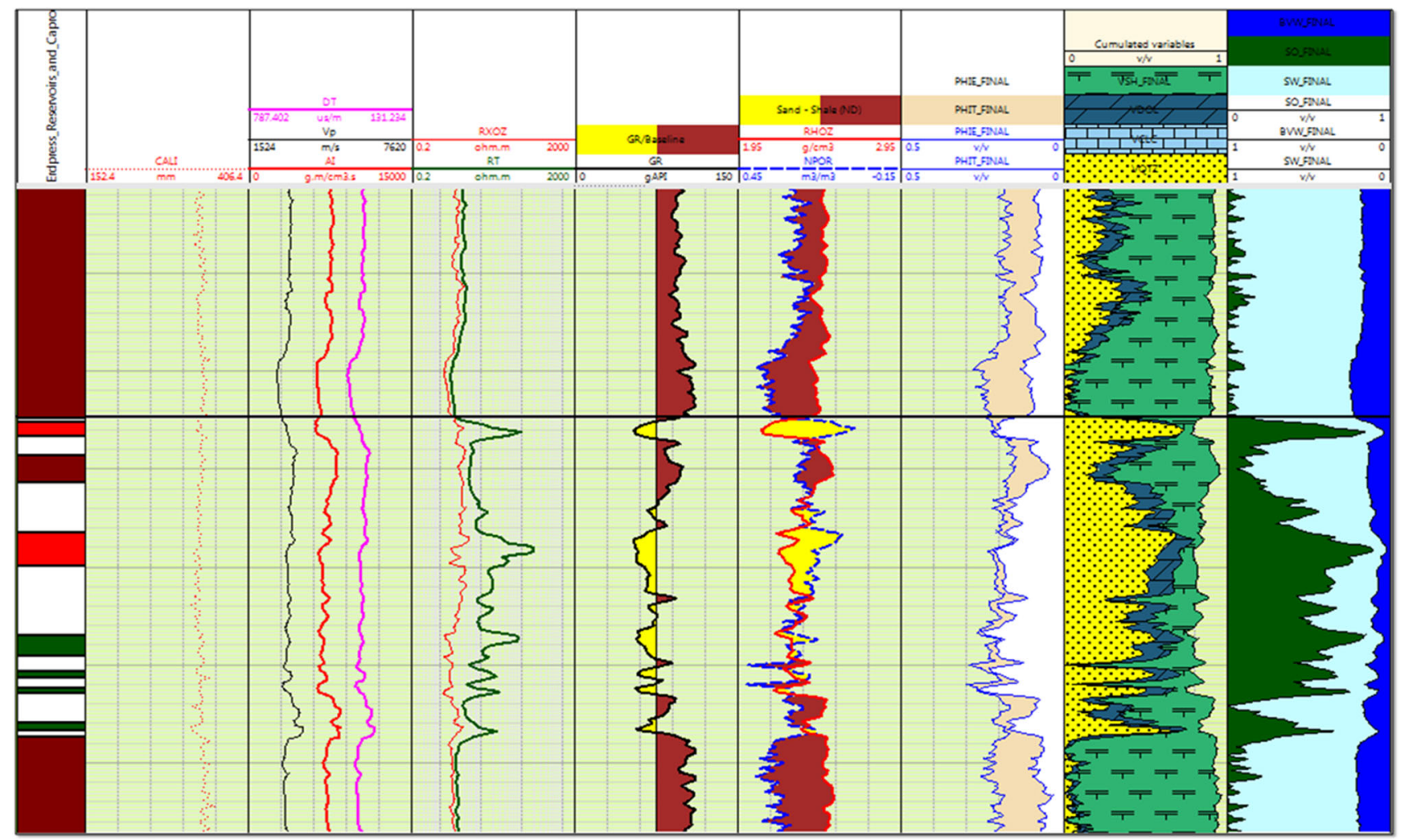

Fig. 2 Lithology interpretation example from one of the sand horizons in the Sarmatian section of the Vienna Basin. The zonation from the first track (red gas; green oil; brown shale) have been used for the creation of the rock physics templates

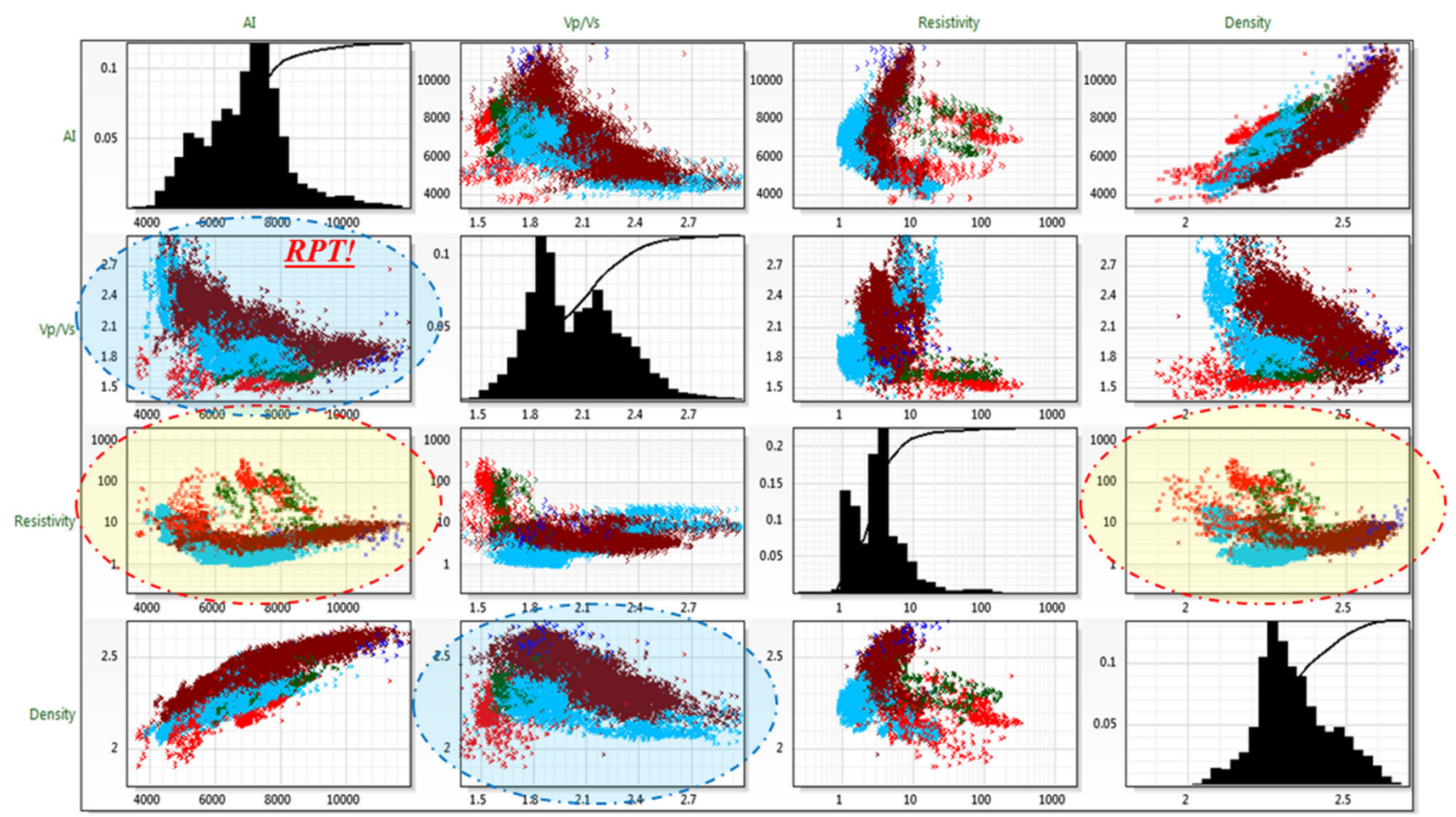

Fig. 3 Scatter plot matrix of AI, $v_{p} / v_{s}$ ratio, resistivity and density for Field A data of the picked sand and shale packages within the Field A wells. Colour scale is lithology-fluid based. Red gas; green oil; blue water; brown shales. Interesting combinations are highlighted 


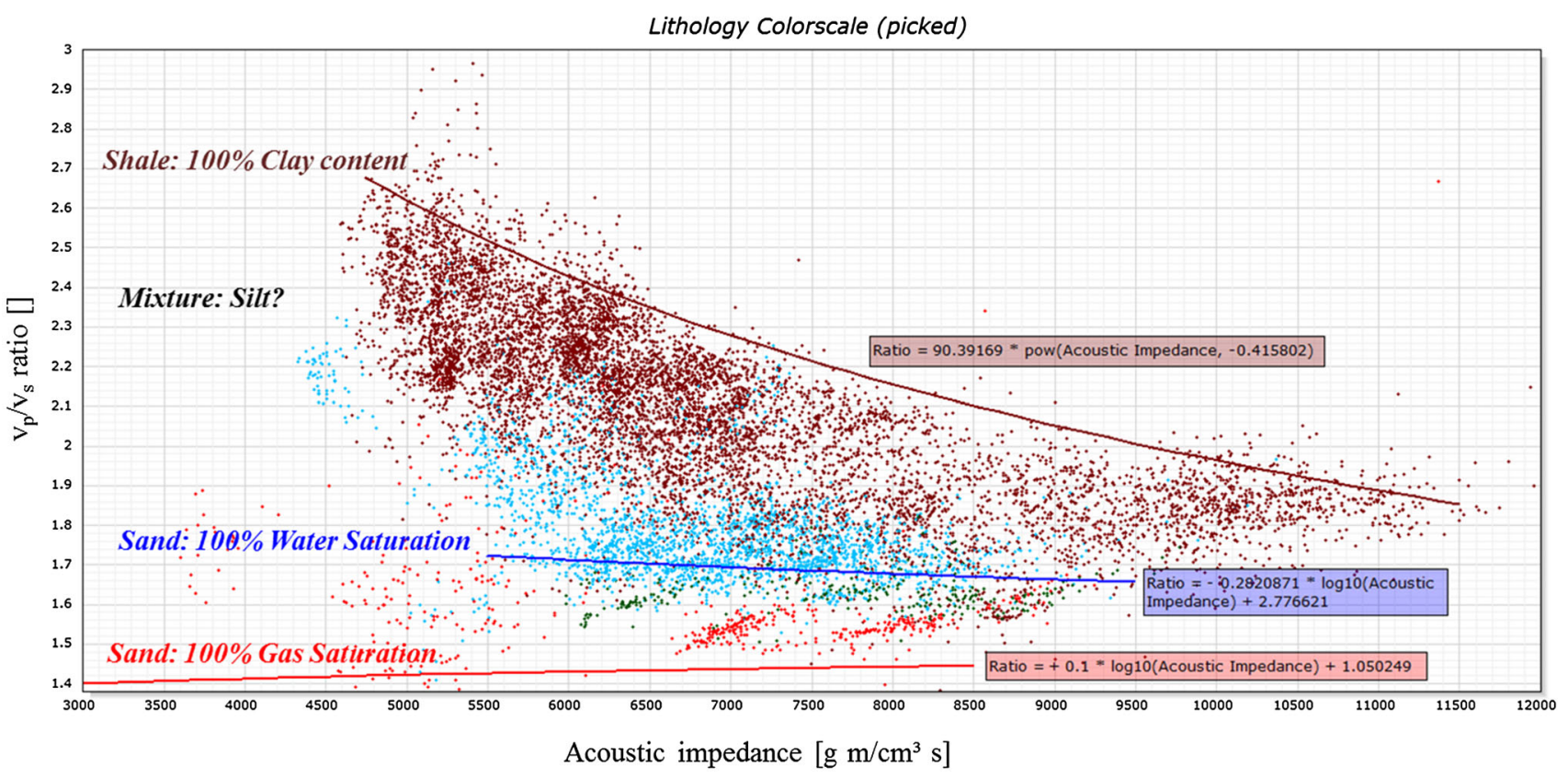

Fig. $4 v_{p} / v_{s}$ versus AI rock physics template with the shale (brown) and sand (red gas; green oil; blue water) zonation from the Field A wells. Modelled shale, water sand and gas sand lines with their equations are displayed too
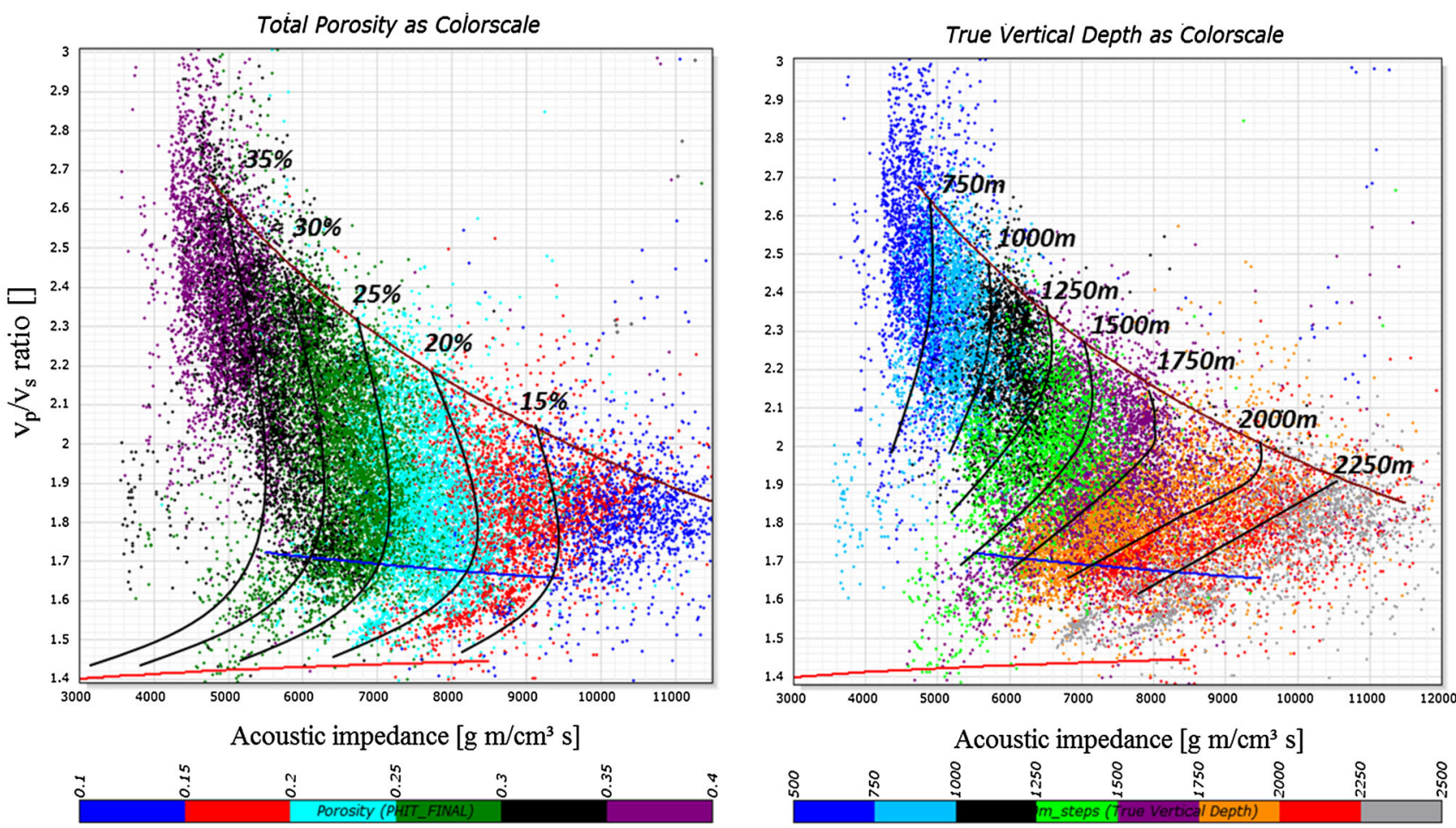

Fig. $5 v_{p} / v_{s}-\mathrm{AI}$ crossplots from all wells (Field A) with modelled shale, water-sand and gas-sand lines. On the left total porosity is used as colour scale and on the right TVD is used as colour scale. Some porosity and TVD isolines are indicated on each crossplot

wells are mainly located in structural lows with the same formations encountered approximately $1.5 \mathrm{~km}$ deeper than the wells from Field A.

Thus, note the different $x$-axes from previous $v_{\mathrm{p}} / v_{\mathrm{s}}-\mathrm{AI}$ crossplots (starting at AI $=7000 \mathrm{~g} \mathrm{~m} / \mathrm{cm}^{3} \mathrm{~s}$ ). As visible in the crossplot, the encountered lithologies, consisting mainly of shales and sands from Badenian, Karpatian and Ottnangian ages of the Field B, C and D wells are fitting very well between the sand and shale line derived from Field A. Ottnangian (first crossplot, brown data points), which consists mainly of shales, 

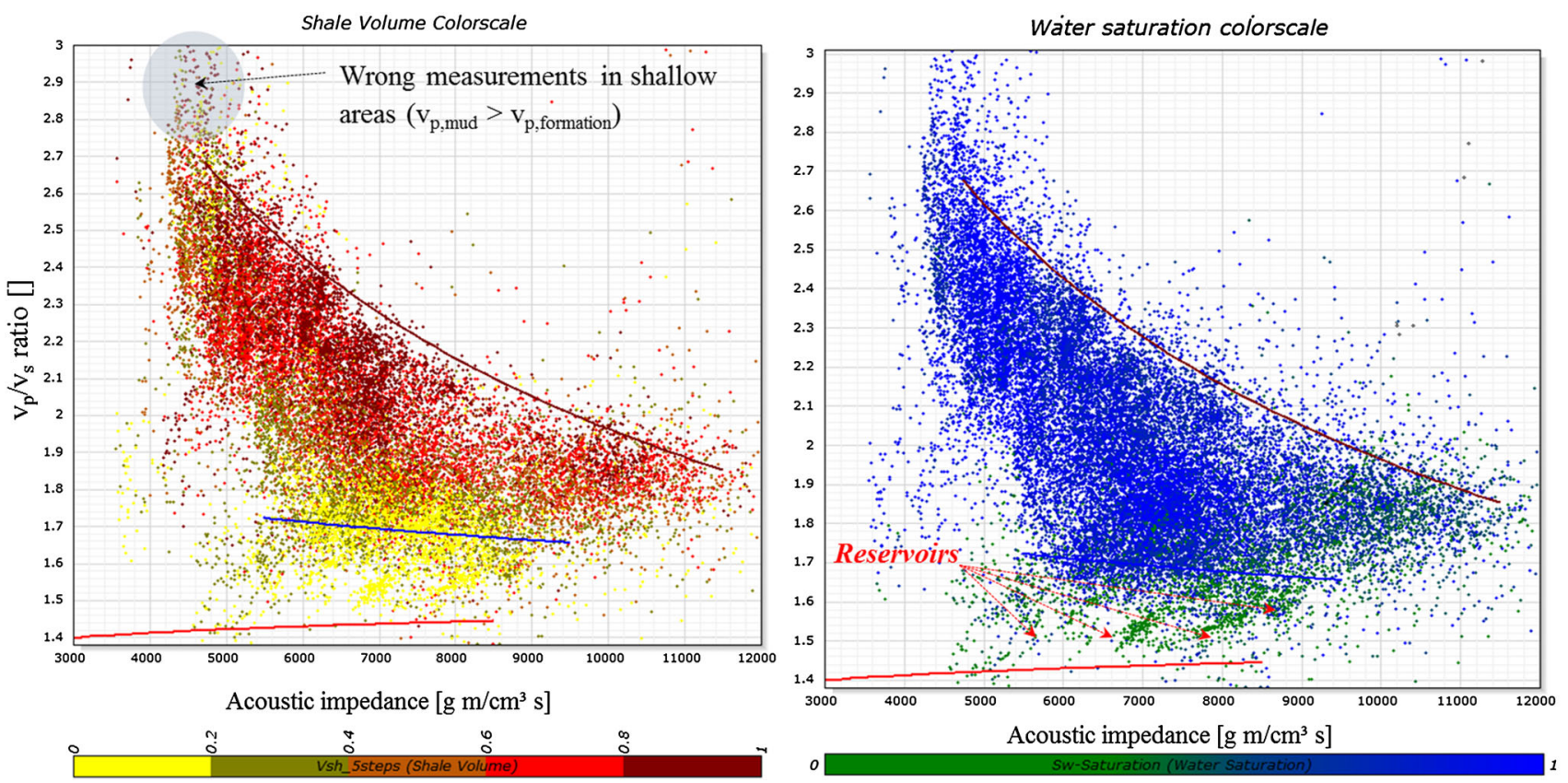

Fig. $6 v_{p} / v_{s}-\mathrm{AI}$ crossplots from wells (Field A) with modelled shale, water-sand and gas-sand lines. On the left calculated shale volume is used as colour scale and on the right calculated water saturation has been used as colour scale
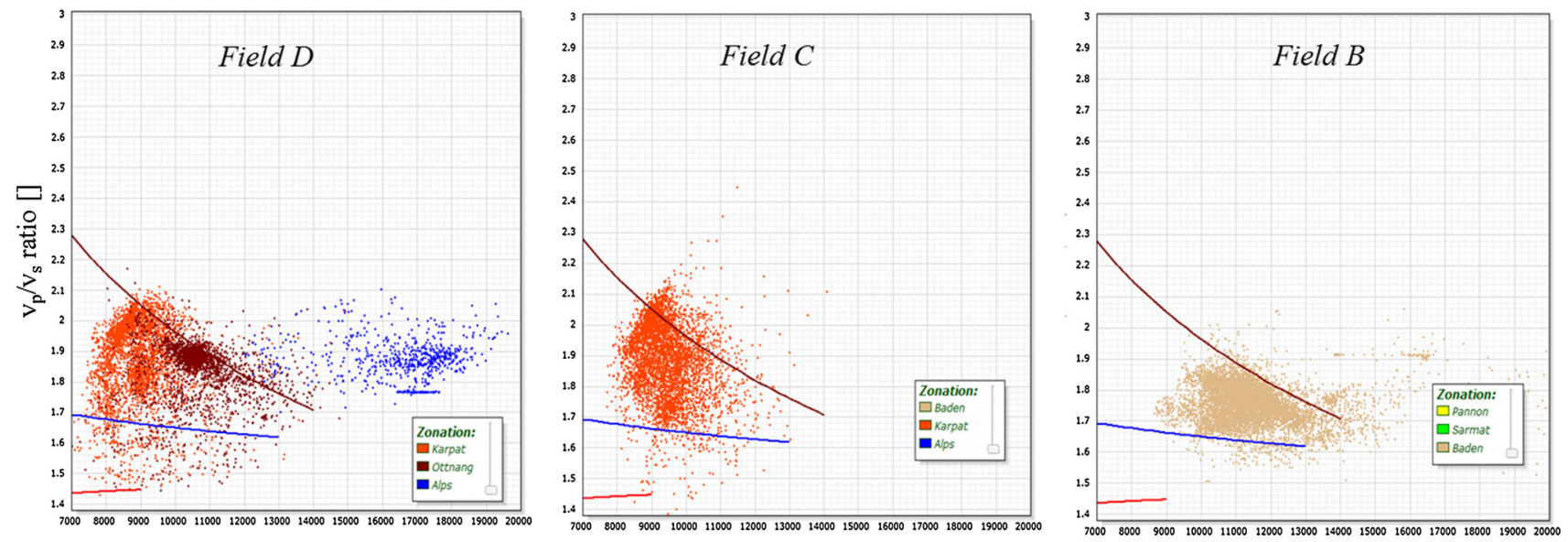

Acoustic impedance $\left[\mathrm{g} \mathrm{m} / \mathrm{cm}^{3} \mathrm{~s}\right]$

Fig. 7 All available data from the remaining wells ( $\mathrm{v}_{\mathrm{s}}$ limiting factor) plotted on a $v_{p} / v_{s}-\mathrm{AI}$ crossplot with shale and sand (water and gas) lines derived from Field A wells. Note that the starting point of

plots slightly below the modelled shale line. "The main dolomite" below the basin, which has been drilled by a well in Field $\mathrm{D}$ plots in area slightly below $v_{\mathrm{p}} / \nu_{\mathrm{s}}$ ratio of 2 and acoustic impedance of above $15000 \mathrm{~g} \mathrm{~m} / \mathrm{cm}^{3} \mathrm{~s}$.

\section{Results and interpretation}

In the following section, lithology and fluid effects and the influence of different depositional sequences within the Vienna Basin on the plotting behaviour and the derived shale the $x$-axes is different from the previous crossplots $\left(7000 \mathrm{~g} \mathrm{~m} / \mathrm{cm}^{3} \mathrm{~s}\right)$ due to the deeper depth of investigated formations

and sand lines within the Neogene sequence of the Vienna Basin, as well as "the main dolomite" beneath will be interpreted and discussed. Additionally, data will be compared to already existing rock physics templates derived by laboratory measurements and petrophysical models.

The created rock physics template follows the trends which has already been shown in numerous studies and discussed and summarized, e.g. by Avseth et al. (2005) or Schön (2015):

- Gas saturation decreases $v_{\mathrm{p}} / v_{\mathrm{s}}$ ratios and acoustic impedance. 


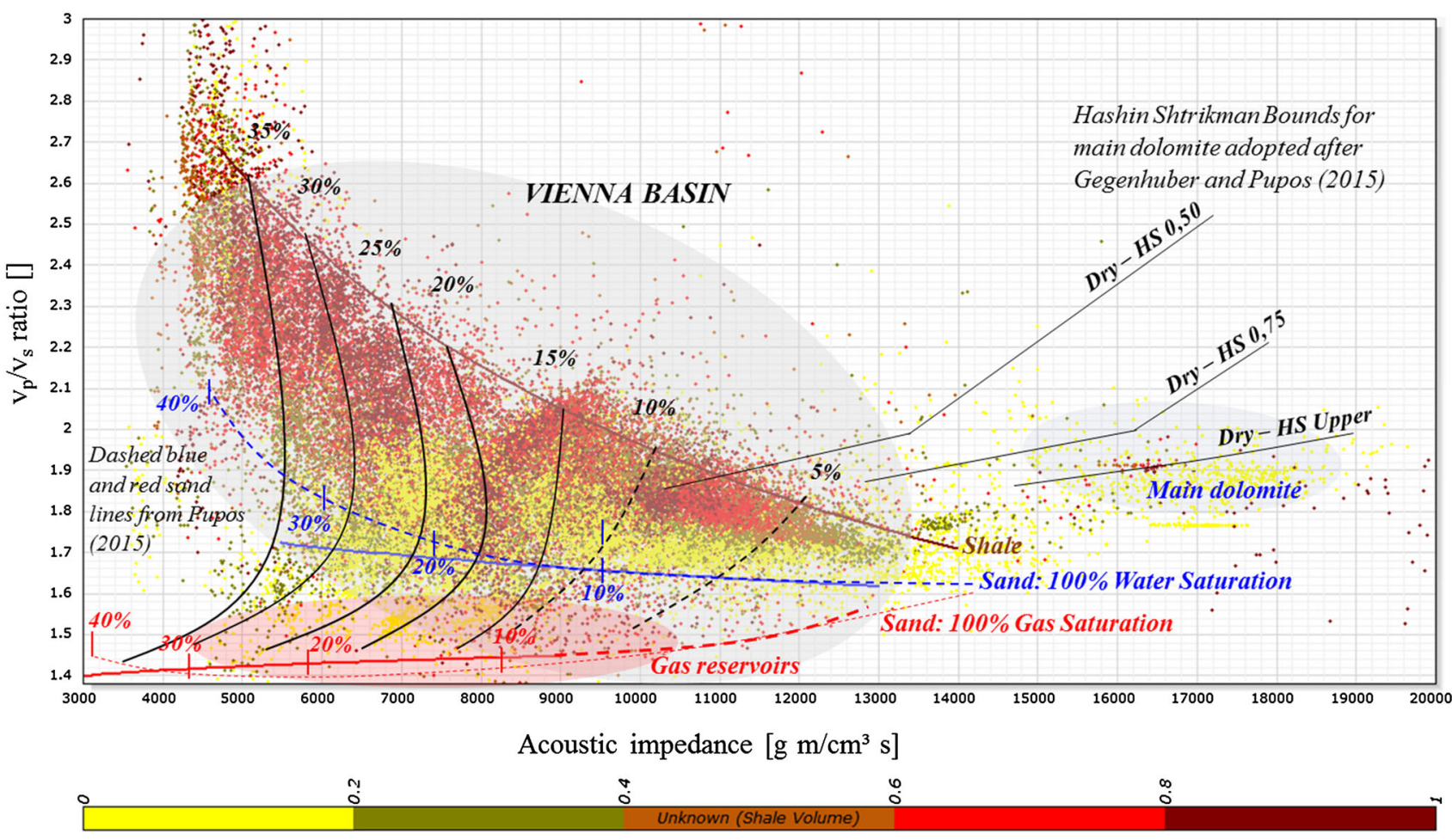

Fig. $8 v_{\mathrm{p}} / \mathrm{v}_{\mathrm{s}}-\mathrm{AI}$ crossplot with determined sand and shale lines; shale volume as colour scale. Porosity isolines from Fig. 5 are indicated too. Two more isolines (10 and $5 \%$ porosity) are estimated.

- Shale content increases $v_{\mathrm{p}} / v_{\mathrm{s}}$ ratios and decreases acoustic impedance.

- Compaction decreases $v_{\mathrm{p}} / v_{\mathrm{s}}$ ratios and increases acoustic impedance.

- Porosity slightly increases $v_{\mathrm{p}} / v_{\mathrm{s}}$ ratios and decreases acoustic impedance.

- Oil-water contrasts are hardly recognized with elastic measurements.

The last point, which states out that oil-water contrasts are hardly recognized with elastic measurements due to similar oil and water densities, is true, but as visible in Fig. 3 the green points (oil-bearing reservoirs) have significantly different plotting areas compared to the blue water-saturated sands. Thus, in Vienna Basin it could be possible to define oil-bearing sand area and to try to read them out of seismic. Gas-bearing horizons are clearly separated from water and oil-bearing sands due to the different elastic properties of the fluids.

The porosity trend shown in Fig. 4 indicates a good correlation with the elastic parameters and the above statement from previous studies is given. However, when looking at different lines (water/gas sand and shale) at same acoustic impedance on the $x$-axis, porosity of gasbearing sand is the lowest followed by shale and last but not least water-bearing sand. This is the same trend shown
Correlation lines for carbonates (Gegenhuber and Pupos 2015) are included. Additionally, sand lines (dashed blue water-saturated and red gas-saturated) (Pupos 2015) are indicated for comparison reasons

in previous studies (e.g. Avseth et al. 2005). In true vertical depth colour-scaled crossplot in the same figure, the true vertical depth gradients show similar behaviour although there are some uncertainties in these isolines as stated out before and visible on the crossplot. Reasons for the uncertainty of true vertical depth trendlines could be the faulting of the basin and the related different compaction rate depending on the, e.g. hanging or footwall side of the fault and the timing of the fault. Another reason for the uncertainty of the true vertical depth lines could be the deviation of the drilled wells and the tool during the measurements. Anisotropic shale formations will result in higher velocity measurements when measured under deviated conditions than when the well is fully vertical at the same true vertical depth and compaction behaviour. Nevertheless, the modelled true vertical depth trend lines still are showing predicted behaviour and can be used for further investigations.

In Fig. 8, all available data from Field A and remaining wells in Vienna Basin are plotted onto $v_{\mathrm{p}} / v_{\mathrm{s}}$-acoustic impedance crossplot with the determined sand and shale lines and porosity trend lines. Colour scale shale volume has been chosen. Porosity isolines from Fig. 5 are indicated too. Two more isolines (10 and 5\% porosity) are estimated (dashed because of uncertainty). 


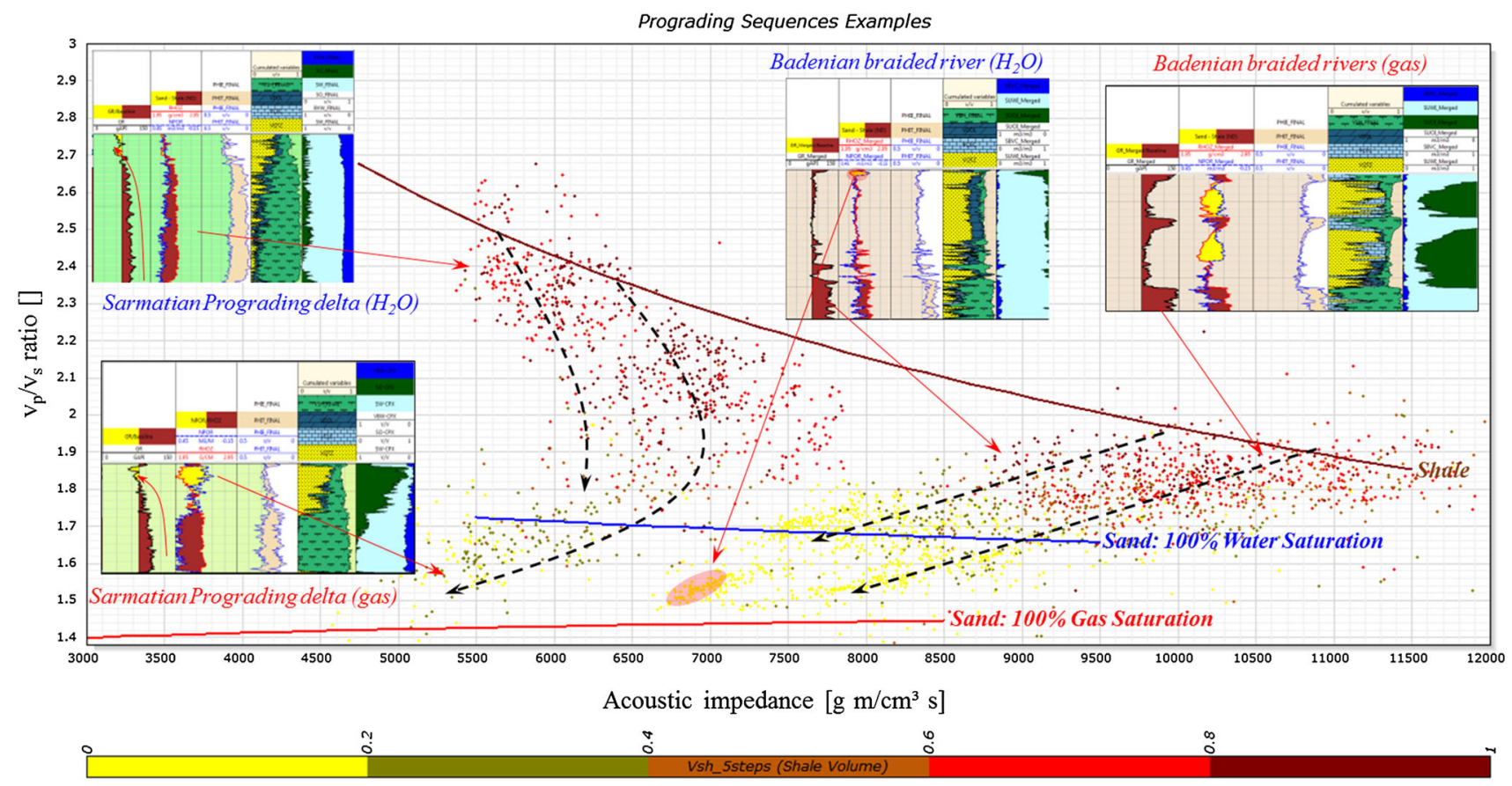

Fig. $9 v_{p} / v_{s}-\mathrm{AI}$ crossplot with determined sand and shale lines. Some selected prograding (and non-prograding) sequences from shallower and deeper areas of the wells are plotted to present their behaviour on

Hashin-Shtrikman bounds from previous work from Gegenhuber and Pupos (2015) on dry (black) carbonate samples (including "main dolomite") are plotted on the right side of the template. Within that study saturated bounds have been derived too, but due to the fact that dolomite here is dry only dry bounds are shown in the crossplot.

Additionally, for comparison reasons data derived from laboratory measurements on plugs (siliciclastic lithology water-bearing and gas-bearing sand) are indicated in dashed thin blue and red lines with the derived porosity. These plugs are from Badenian age sand reservoirs from Vienna Basin and modelled with petrophysical models (Cement models (Dvorkin and Nur 1996 and Avseth et al. 2000), Hashin-Shtrikman bounds (1962), and Gassmann fluid substitution (Gassmann 1951). The lines are results of an unpublished master thesis related to rock physics templates in Vienna Basin (Pupos 2015).

As visible, there are two main areas of the crossplot. Data points from the Neogene (Miocene) siliciclastic lithology of the Vienna Basin itself are on the left side with lower acoustic impedance values and data points from the northern Calcareous Alps, i.e. the dense and low-porosity "main dolomite" are on the right side in areas of higher acoustic impedance values. Therefore, a kind of petrographic code (=influence of mineralogy/lithology) is visible. When considering the shale volume colour scale of all the rock physics template. Log view from plotted data is displayed to get a better understanding

available data, the shale and sand lines fit very well to the data. Below the blue $100 \%$ water saturation line most of the data are taken from hydrocarbon-bearing reservoirs, above the sand is less clean.

Equations 1-3 below represent the sand and shale regression lines which have been derived through the curve fitting on the well data as described in the methodology chapter.

Shale: $\frac{V_{p}}{V_{s}}=90.4 \cdot \mathrm{AI}^{-0.416}$

Sand (water): $\frac{V_{p}}{V_{s}}=-0.2821 \cdot \log _{10}(\mathrm{AI})+2.777$

Sand (gas): $\frac{V_{p}}{V_{s}}=0.1 \cdot \log _{10}(\mathrm{AI})+1.0503$

When comparing the sand lines to the laboratory and model equation-derived sand lines from Pupos (2015), the log-derived data fit very well the laboratory-derived data in areas of higher acoustic impedance. There are some misfits (including resistivity) especially in areas of lower acoustic impedance with the water-saturated sand line. These deviation results from the fact that the model-based lines are calculated and extrapolated from data from an exact lithology and certain reservoir in Badenian time. Thus, homogenous lithology is presupposed throughout the whole well. The data derived from logs take different 


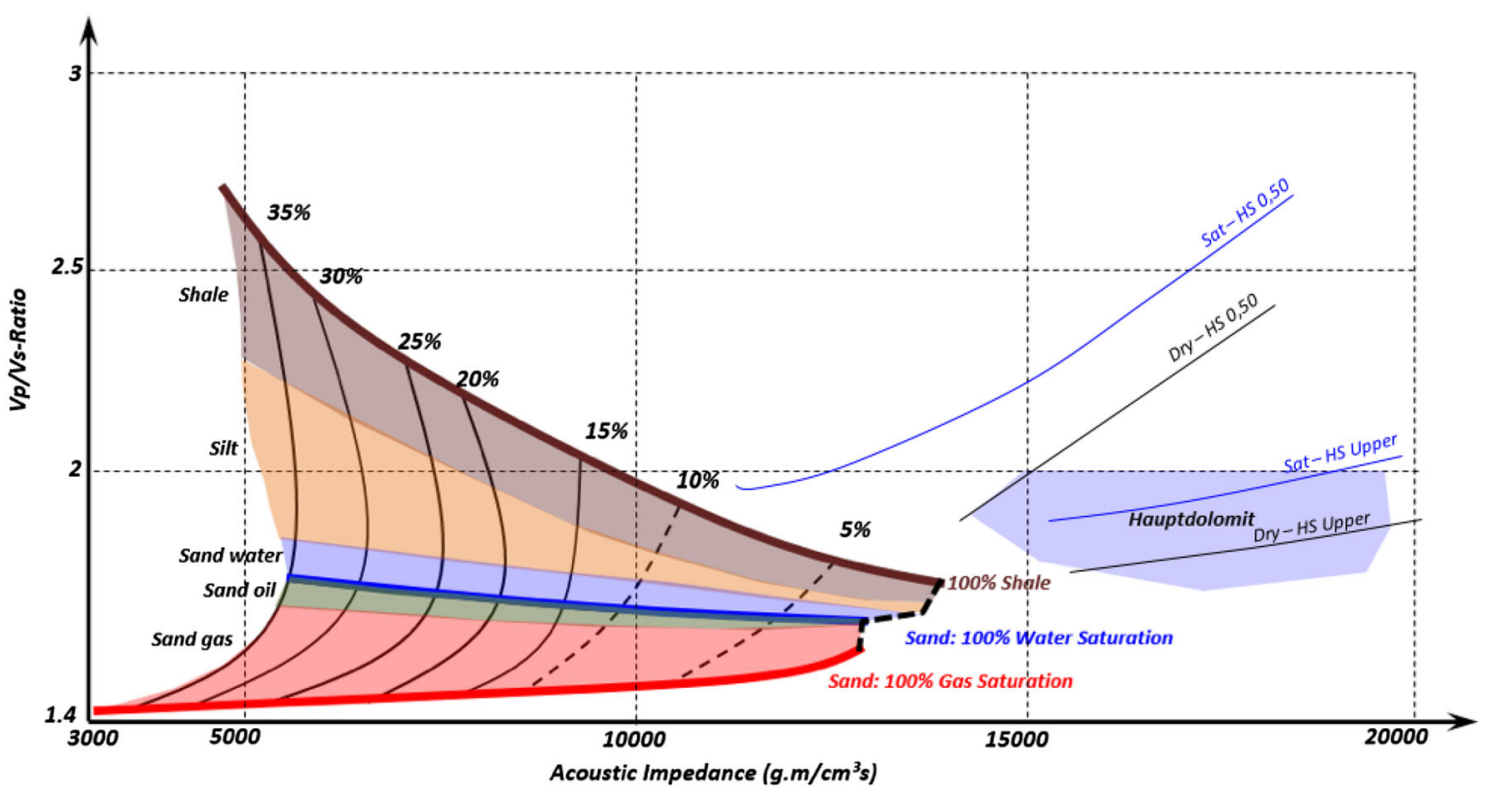

Fig. 10 Final rock physics template applicable for Vienna Basin with indicated lithologies and fluids as well as porosity trend lines. Additionally, HS bounds for carbonates (Gegenhuber and Pupos 2015) are included

lithologies into account and can be used more generally throughout the basin.

Gegenhuber and Pupos (2015) measurements and the derived upper bounds for carbonate (including "the main dolomite") samples fit well to the data points from well measurements in Field D where "the main dolomite" has been reached. Formation evaluation indicates a dense and low-porosity dolomite, which explains that the upper HS bounds fit to the data.

Regarding the "mixture lithology" between the watersaturated sand line and shale line, a closer look is taken with some examples of depositional sequences. Figure 9 below shows depositional trends within the rock physics template with the aid of some selected reservoir examples from Sarmatian and Badenian ages. Two coarsening upward trends (due to delta deposition in Sarmatian) are presented on the left side of the plot. In general, the fine (clay) part of the delta plots near the predicted shale line as it should be. When the grains become coarser and the sand takes over, the data points shift into the direction of higher $\mathrm{AI}$ and lower $v_{\mathrm{p}} / v_{\mathrm{s}}$ ratios towards the sand line. In further consequence, there are two possibilities of plotting behaviour: if the sand is filled with gas the trend reverses again into the direction of gas or if the sand on the top of the depositional sequence is filled with water or oil the data points stays near the water line.

On the right side of the crossplot two Badenian reservoirs deposited within braided rivers are shown as example. The left reservoir is a shallower Badenian horizon which is water-bearing in the shown example; while the right reservoir is around $50 \mathrm{~m}$ deeper Badenian horizon which has two gas-bearing very clean sand packages. They are both shifting in the direction of the water- and gassaturated sand lines when the sand fraction amount is increasing, but they do not follow the reversal trend (from shale to sand) like the shallower Sarmatian prograding delta reservoirs in the left part of the crossplot.

Shales plot in higher AI areas and sands plot in lower AI areas. Reason for this behaviour could be the faster compaction of shales with depth and the reversal of the trend as we have encountered within the Sarmatian reservoirs. Another explanation for the missing of the reversal trend could be the deviation of the wells and the anisotropic behaviour of the shales. As already mentioned, with increasing tool deviation within the borehole, velocity measurements (which are included in the acoustic impedance calculation) are apparently increasing because of the anisotropic shale layers. At the same time, they remain stable in sands independent of deviation. Because most of the wells used are deviated after a certain depth (most of the cases from $1.5 \mathrm{~km}$ ), this could play a major role here.

\section{Conclusion and outlook}

A general rock physics template for Vienna Basin derived fully from log data is created throughout the study. This final template including the carbonate bounds (saturated and dry) from Gegenhuber and Pupos (2015) is shown in Fig. 10. 
It is shown that the template created with formation evaluation data honours lithological heterogeneity throughout the basin. Additionally, it is shown that laboratory-derived templates with petrophysical models fit the well data very well in greater depths, but in shallower areas there are misfits because of the assumed homogeneity of the lithology in experimentally derived data and limited cores. Examples of depositional sequences with shale and sand parts (braided rivers and prograding deltas) behave as predicted within the rock physics template. Concluding, the template from well-log data represents the general basin lithology very well even in different areas of the basin. Fluid discrimination in the reservoir sands is given on the template too. Even oil-bearing sands show some significant discrimination from water-bearing sands. Thus, in further consequence inversion results from seismic data sets from different parts of the Vienna Basin will be used to screen the basin for commercial reservoirs. Additionally, further work will include true vertical depth into next templates as part of the axis, due to the fact, that this property correlates with elastic properties and is derivable from seismic data.

Acknowledgements Open access funding provided by Montanuniversität Leoben. The authors would like to thank OMV for the permission to publish data.

Open Access This article is distributed under the terms of the Creative Commons Attribution 4.0 International License (http://crea tivecommons.org/licenses/by/4.0/), which permits unrestricted use, distribution, and reproduction in any medium, provided you give appropriate credit to the original author(s) and the source, provide a link to the Creative Commons license, and indicate if changes were made.

\section{References}

Avseth P, Carcione J (2015) Rock physics template analysis of Norwegian shelf clay-rich source rocks. Third EAGE workshop on rock physics, extended abstracts: RP23

Avseth P, Veggeland T (2015) Seismic screening of rock stiffness and fluid softening using rock physics attributes. Interpretation 3:85-93. doi:10.1190/INT-2015-0054.1

Avseth P, Dvorkin J, Mavko G, Rykkje J (2000) Rock physics diagnostic of North Sea sands: link between microstructure and seismic properties. Geophys Res Lett 27:2761-2764. doi:10. 1029/1999GL008468

Avseth P, Mukerji T, Mavko G (2005) Quantitative seismic interpretation: applying rock physics tools to reduce interpretation risk. Cambridge University Press, Cambridge

Avseth P, van Wijngaarden AJ, Mavko G (2009) Rock physics estimation of cement volume, sorting, and net-to-gross in North Sea sandstones. Lead Edge 28:98-108. doi:10.1190/1.3064154
Ba J, Cao H, Carcione J, Tang G, Yan XF, Sun WT, Nie JX (2013) Multiscale rock physics templates for gas detection in carbonate reservoirs. J Appl Geophys 93:77-82. doi:10.1016/j.jappgeo. 2013.03.011

Chi XG, Han DH (2009) Lithology and fluid differentiation using rock physics template. Lead Edge 28:1424-1428. doi:10.1190/1. 3064147

Dvorkin J, Nur A (1996) Elasticity of high-porosity sandstones: theory for two North Sea datasets. Geophysics 61:1363-1370. doi:10.1190/1.1444059

Gassmann F (1951) Elastic waves through a packing of spheres. Geophysics 16:673-685

Gegenhuber N, Pupos J (2015) Rock physics template from laboratory data for carbonates. J Appl Geophys 114:12-18. doi:10.1016/j. jappgeo.2015.01.005

Gupta S, Chatterjee R, Farooqui M (2012) Rock physics template (RPT) analysis of well logs and seismic data for lithology and fluid classification in Cambay Basin. Int $J$ Earth Sci 101:1407-1426. doi:10.1007/s00531-011-0736-1

Hamilton W, Wagner L, Wessely G (1999) Oil and gas in Austria. Mitt Österr Geol Ges 92:235-262

Hashin Z, Shtrikman S (1962) A variational approach to the theory of effective magnetic permeability of multiphase materials. J Appl Phys 33:3125-3131

Hermana M, Lubis LA, Ghosh PD, Sum CW (2016) New rock physics template for better hydrocarbon prediction. Offshore technology conference Asia, OTC-26538-MS

Kienberger G, Fuchs R (2006) Case history of the Matzen Field/ Matzen Sand (16th TH): a Story of success! Where is the end? SPE Europec/EAGE annual conference and exhibition, SPE 100329

Kreutzer N (1992) Matzen Field, Austria (Vienna Basin). AAPG treatise of petroleum geology. Atlas of Oil and Gas Fields, Structural Traps VII, pp 57-98

Ladwein HW (1988) Organic geochemistry of Vienna Basin: model for hydrocarbon generation in overthrust belts. AAPG Bulletin 72:586-599

Ødegaard E, Avseth P (2004) Well log and seismic data analysis using rock physics templates. First Break 22:37-43. doi:10.3997/ 1365-2397.2004017

Pupos J (2015) „Rock physics template“-application on different rocks and different scales. Unpublished Master Thesis, Montanuniversitaet Leoben, Austria

Sachsenhofer RF (2001) Syn- and post-collisional heat flow in the Cenozoic Eastern Alps. Int J Earth Sci 90:579-592

Sauer R, Seifert P, Wessely G (1992) Guidebook to excursions in the Vienna Basin and the adjacent Alpine-Carpathian thrustbelt in Austria. Mitt Oesterr Geol Ges 85:1-264

Schön JH (2015) Physical properties of rocks: fundamentals and principles of petrophysics. Elsevier, Amsterdam

Tucovic N, Bartetzko A, Wessling S, Schön J, Gegenhuber N (2016) Resistivity and acoustic impedance based rock physics templates for enhanced well placement and reservoir understanding. 78th EAGE conference and exhibition, extended abstracts, We STZ013

Wessely G (2006) Geologie der Österreichischen Bundesländer, Niederösterreich. Geologische Bundesanstalt, Wien, pp 189-226 